\title{
Honesty and integrity in published science and engineering papers - opinion
}

Peter C. Hewlett BSc, PhD, LLD, CChem, CSci, FRSC, FIM, FICT, FConcSOC

Professor, University of Dundee; R \& D Director, David Ball Group,

Cambridge, UK

There appears to be the perception of a growing occurrence of plagiarism and dishonesty in some published papers (Anon, 2021). It is important to have a manner/policy of responding when and if they do occur.

It is reasonable when dealing with research scientists and professional engineers that personal reputation and integrity can be assumed. The alternative assumption would render communication and publication difficult and, I suggest, potentially unpleasant. As for the Magazine of Concrete Research (MCR) when reviewing submitted papers, it is assumed the authors have integrity.

When publishing a paper, authors are exposed to examination by their contemporaries. This is healthy and can result in exchanges by interested parties - this is to be encouraged. In this regard, authors would be foolish to knowingly transgress or cheat. There might be occasions when a naive or clumsy comment may give rise to accusations but these can be dealt with author-to-author in a rectifying way. Better to adopt such an approach without resorting to defamatory accusations that possibly lead to legal consequences. Surely dialogue between authors is better than confrontation. In this regard, the editorial office is a 'go between', making the author aware of the reader complaint and endeavouring to resolve the issue.
However, when there is good reason (resulting from a complaint) to doubt an author's integrity, it is important that the complainant should not be anonymous. To be otherwise could put the publisher of scientific, technical and engineering material in a similar situation to the type of abuse observed on social media - where unproven and anonymous accusations can be made with impunity. In the case of the MCR, in order to protect a complainant's identity, we would guarantee confidentiality. This should mitigate concern about remaining anonymous.

When it is clear that there is evidence of plagiarism and a case to be answered, the MCR, in principle, would adopt the response method set out by the Committee on Publication Ethics (COPE), of which ICE Publishing is a member. This methodology, whilst being objective, can result in extending the process of enquiry and result in increased costs and delaying publication whilst not guaranteeing an acceptable outcome. On balance, isn't assuming trust and personal professionalism in our authors a better starting point than distrust? However, adopting this approach puts the responsibility on authors to resolve disputes initially.

Resolution is better than confrontation.

\section{REFERENCE}

Anon (2021) Retraction notice. Magazine of Concrete Research 73(24): 1296, https://doi.org/10.1680/jmacr.2021.73.24.1296. 